\title{
A prospective randomized control trial -Comparison of hemodynamic response to laryngoscopy and intubation - Macintosh versus McCoy blade
}

\author{
Madhavi R. Godbole ${ }^{1, *}$, Girish Saundattikar ${ }^{2}$ \\ ${ }^{1}$ Assistamt Professor, ${ }^{2}$ Professor \& HOD, Dept. of Anaesthesia, Smt. Kashibai Navale Medical College and Hospital, Pune, \\ Maharashtra, India
}

*Corresponding Author:

Email: madhavigodbole30@gmail.com

Received: $07^{\text {th }}$ October, 2017

Accepted: $21^{\text {st }}$ February, 2018

\begin{abstract}
Introduction: As is well described laryngoscopy and intubation produce significant hemodynamic response. It is shown in previous studies that type of laryngoscope blade used affects the degree of hemodynamic response to endotracheal intubation. In our study we have attempted to compare hemodynamic response to laryngoscopy and intubation using Macintosh and McCoy blade.

Aim: Our aim was to perform comparative study of hemodynamic response to laryngoscopy and intubation using Macintosh versus McCoy blade.

Materials and Methods: A prospective randomized controlled study comparing hemodynamic response to laryngoscopy and intubation using Macintosh and McCoy blade was conducted. A total no. of Sixty patients, either male or female, between age group of 20 -50yrs, belonging to American Society of Anaesthesiology physical status I and II requiring General anaesthesia were randomly allocated to either group A (Macintosh group) or group B (McCoy group) In both the groups, standard methods were used. Comparison of hemodynamic parameters i.e. Heart rate (HR), systolic (SBP) diastolic (DBP) and mean blood pressure (MAP) was done at induction, during laryngoscopy and intubation, till 5 mins after intubation.

Statistical Analysis: Hemodynamic changes in between the two groups were compared statistically using Unpaired "t" tests.

Results: Significant rise in all HR, SBP, DBP, MAP was seen in both the groups after laryngoscopy and intubation. In group A the rise was found to be statistically significant as compared to group B.

Conclusion: This study helped us to conclude that McCoy blade produces reduced hemodynamic response to laryngoscopy and intubation as compared to Macintosh blade.
\end{abstract}

Keywords: Hemodynamic response, Intubation, Laryngoscopy, Macintosh and McCoy blade.

\section{Introduction}

Reflex release of catecholamines, following laryngoscopy and intubation results in cardiovascular response like tachycardia, dysrythmias and hypertension. These responses are self-limiting but can lead to deleterious respiratory, neurological \& cardiovascular effects in morbid patients. Intubation response to laryngoscopy and intubation begins at 15 secs and peak effect is seen at 45 secs. $^{1}$

To attenuate this hemodynamic response different methods like pharmacological interventions (both intravenous and topical) $)^{2-8}$ use of modified instruments ${ }^{9}$ and use of other supraglottic devices (e.g. LMA) $)^{10,11}$ was tried.

McCoy laryngoscope was introduced in 1993. The McCoy blade has a flexible tip and it was postulated that due to this modification, force exerted on the stretch receptors is reduced and thus hemodynamic response is decreased. ${ }^{12}$ In a study by Nishiyama et al it was observed that pressor response was minimal with McCoy blade as compared to Macintosh, Miller blade. ${ }^{9}$

\section{Materials and Methods}

After institutional ethical committee approval and written informed consent, a prospective randomized study was carried out in Dept. of Anaesthesia, SKNMCGH, Pune. A total of 60 patients of either sex between $20-50 y r s$ belonging toAmerican Society of Anaesthesiology physical status I and II posted for elective surgeries under general anaesthesia requiring intubation were enrolled in the study. In our study we excluded patients with anticipated difficult intubation (MPC grade III and grade IV). The study patients were randomly allocated to either group. This Randomization was done by using Computer generated random number tables. This was done by a separate anaesthesiologist who was not involved in performing the laryngoscopy and data collection in the study.

On preoperative day, pre-anesthesia checkup was done, including routine checkup and airway assessment. Written informed consent was taken and all patients were kept nil by mouth overnight. Patient allocation was done randomly by computerized method into two groups, before induction.

Group A: $(n=30)$ conventional Macintosh blade was used.

Group B: (n=30) McCoy blade was used.

Patients were premedicated with Inj. Midazolam $0.03 \mathrm{mg} / \mathrm{kg}$, Inj. Pentazocine $0.5 \mathrm{mg} / \mathrm{kg}$, Inj. Glycopyrrolate $0.04 \mathrm{mg} / \mathrm{kg}$ and Inj. ondansetron 0.08 
$\mathrm{mg} / \mathrm{kg}$ intravenously. Induction of anaesthesia was done using standard technique with Inj. Thiopentone Sodium $3-5 \mathrm{mg} / \mathrm{kg}$ IV and Inj. scoline $1.5-2 \mathrm{mg} / \mathrm{kg}$ to facilitate intubation with appropriate size cuffed endotracheal tube (CETT) no. 7/7.5 for females and 8/8.5 for males. In all cases the endotracheal tube cuff was inflated with air using a syringe, gradually till there was no leak. We noted the hemodynamic parameters HR, SBP, DBP, MAP at different times as follows i.e. baseline (TB), just before laryngoscopy (T0), during laryngoscopy (TL), $1 \mathrm{~min}$ after intubation (T1), $3 \mathrm{~min}$ after intubation (T3), 5 min after Intubation. ECG and Spo2 monitoring was done during the study.Laryngoscopy was performed by expert anaesthesiologist and duration was limited to $15-20$ seconds. Cases where laryngoscopy time exceeded more than 20 secs were excluded from the study. Rest of the anaesthesia was maintained as per the surgical requirement of the patient. At the end of surgery patient was reversed and extubated.
Sample size calculation was done with the Two Independent Sample Mean Formula. Using this formula, comparison between the two groups Macintosh group and McCoy group needed a sample size of 25 in each group to detect an effect size of $6 \mathrm{~mm}$ $\mathrm{Hg}$ in the systolic pressure at a standard deviation (SD) of 7.31 with a power of $80 \%$ and alpha error of 0.05 . Hence, we included 30 patients allowing for $15 \%$ dropouts. Data was compiled in Excel sheet and analyzed. Unpaired " $\mathrm{t}$ " tests were used for statistical analysis of laryngoscopy, intubation and hemodynamic parameters. $\mathrm{P}$ value $<0.05$ was considered statistically significant.

\section{Results}

In our group total 60 patients were compared, 30 belonging to each group. The demographic profile and baseline hemodynamic parameters in both the groups, Group A (Macintosh group) and Group B (McCoy group) were comparable. (Table 1)

Table 1: Demographic Table and Baseline Parameters

\begin{tabular}{|l|c|c|c|}
\hline \multicolumn{1}{|c|}{ Parameters } & $\begin{array}{c}\text { Group A (n=30) } \\
\text { Macintosh Group }\end{array}$ & $\begin{array}{c}\text { Group B (n=30) } \\
\text { McCoy Group }\end{array}$ & P value \\
\hline Age in Yrs (Mean \pm SD) & $33.04 \pm 8.56$ & $35 \pm 7.33$ & $>0.05$ \\
\hline Weight in kg (Mean \pm SD) & $59.08 \pm 7.67$ & $62.10 \pm 8.45$ & $>0.05$ \\
\hline Sex (M/F) & $24 / 26$ & $22 / 28$ & $>0.05$ \\
\hline Heart rate & $77.33 \pm 13.75$ & $71.80 \pm 8.87$ & $>0.05$ \\
\hline Systolic blood pressure & $120.27 \pm 8.45$ & $116.87 \pm 8.28$ & $>0.05$ \\
\hline Diastolic blood pressure & $71.53 \pm 8.83$ & $68.27 \pm 7.77$ & $>0.05$ \\
\hline Mean arterial pressure & $87.78 \pm 7.13$ & $84.58 \pm 5.14$ & $>0.05$ \\
\hline
\end{tabular}

During laryngoscopy (TL) there was rise in heart rate in both the groups, but in group A (Macintosh group) the mean heart rate was $(104.2 \pm 16.77)$ while in group $\mathrm{B}$ (McCoy grp) it was $(93.93 \pm 6.98)(\mathrm{p}=0.002)$ The difference remained significant till 5mins after laryngoscopy ( $<<0.001)$ [Fig .1 and Table 5]

The mean systolic blood pressure, i.e. (TL) during laryngoscopy in group A(Macintosh group) was (149 $.73 \pm 17.47)$ while in group B (McCoy group) it was $(125.27 \pm 7.19)[p<0.001]$ Here the difference remained statistically significant till 4 mins after laryngoscopy . $(\mathrm{p}<0.001)$ [Fig. 2 and Table 2] With mean diastolic blood pressure we found statistically significant difference in the two groups at $1 \mathrm{~min}$ after laryngoscopy group A (94.73 $\pm 10.55)$ and group B ( $85.27 \pm 10.04)$ [p=0.001] [Fig. 3 and Table 3]

As seen in [Fig. 4] the mean Mean arterial pressure during laryngoscopy (TL) in group A was $(109.42 \pm 11.95)$ and group B (102.42 \pm 7.27$)$ The difference remained significant till $5 \mathrm{mins}$ after laryngoscopy ( $<<0.001)$ [Fig .4 and Table 4]

Table 2: SBP taken at different timings and corresponding $P$ Values

\begin{tabular}{|l|c|c|c|c|c|}
\hline \multirow{2}{*}{ SBP at } & \multicolumn{2}{|c|}{ Macintosh $(\mathbf{n}=\mathbf{3 0})$} & \multicolumn{2}{c|}{ McCoy $(\mathbf{n}=\mathbf{3 0})$} & \multirow{2}{*}{ P Value } \\
\cline { 2 - 5 } & Mean & SD & Mean & SD & \\
\hline TB & 120.27 & 8.45 & 116.87 & 8.28 & 0.121 \\
\hline T0 & 116.27 & 8.69 & 112.13 & 7.94 & 0.059 \\
\hline TL & 149.73 & 17.47 & 125.27 & 7.19 & $<0.001^{*}$ \\
\hline T1 & 147.33 & 10.83 & 121.93 & 9.36 & $<0.001^{*}$ \\
\hline T3 & 129.07 & 13.11 & 112.07 & 8.76 & $<0.001^{*}$ \\
\hline T5 & 111.93 & 13.52 & 106.20 & 7.56 & $0.049^{*}$ \\
\hline
\end{tabular}


Table 3: DBP taken at different timings and corresponding $P$ Values

\begin{tabular}{|l|c|c|c|c|c|}
\hline \multirow{2}{*}{ DBP at } & \multicolumn{2}{|c|}{ Macintosh $(\mathbf{n}=\mathbf{3 0})$} & \multicolumn{2}{|c|}{ McCoy $(\mathbf{n}=\mathbf{3 0})$} & \multirow{2}{*}{ P Value } \\
\cline { 2 - 5 } & Mean & SD & Mean & SD & \\
\hline TB & 71.53 & 8.83 & 68.27 & 7.77 & 0.134 \\
\hline T0 & 69.93 & 7.02 & 72.60 & 8.55 & 0192 \\
\hline TL & 89.27 & 12.12 & 91.00 & 10.53 & 0.557 \\
\hline T1 & 94.73 & 10.55 & 85.27 & 10.04 & $0.001^{*}$ \\
\hline T3 & 81.60 & 10.05 & 73.90 & 9.95 & $0.004^{*}$ \\
\hline T5 & 74.53 & 8.42 & 65.27 & 8.28 & $<0.001^{*}$ \\
\hline
\end{tabular}

Table 4: MAP taken at different timings and corresponding $P$ Values

\begin{tabular}{|l|c|c|c|c|c|}
\hline \multirow{2}{*}{ MAP at } & \multicolumn{2}{|c|}{ Macintosh $(\mathbf{n}=\mathbf{3 0})$} & \multicolumn{2}{c|}{ McCoy $(\mathbf{n}=\mathbf{3 0})$} & \multirow{2}{*}{ P Value } \\
\cline { 2 - 5 } & Mean & SD & Mean & SD & \\
\hline TB & 87.78 & 7.13 & 84.58 & 5.14 & 0.051 \\
\hline T0 & 85.38 & 6.16 & 85.78 & 5.58 & 0.793 \\
\hline TL & 109.42 & 11.95 & 102.42 & 7.27 & $0.009^{*}$ \\
\hline T1 & 112.27 & 8.31 & 97.49 & 7.81 & $<0.001^{*}$ \\
\hline T3 & 97.42 & 9.07 & 86.62 & 7.55 & $<0.001^{*}$ \\
\hline T5 & 87.00 & 6.95 & 78.91 & 6.27 & $<0.001^{*}$ \\
\hline
\end{tabular}

Table 5: HR taken at different timings and corresponding $P$ Values

\begin{tabular}{|l|c|c|c|c|c|}
\hline \multirow{2}{*}{ HR at } & \multicolumn{2}{|c|}{ Macintosh $(\mathbf{n}=\mathbf{3 0})$} & \multicolumn{2}{c|}{ McCoy $(\mathbf{n}=\mathbf{3 0})$} & \multirow{2}{*}{ P Value } \\
\cline { 2 - 5 } & Mean & SD & Mean & SD & \\
\hline TB & 77.33 & 13.75 & 71.80 & 8.87 & .069 \\
\hline T0 & 88.23 & 10.13 & 85.40 & 7.56 & 0.225 \\
\hline TL & 104.20 & 16.77 & 93.93 & 6.98 & $0.002^{*}$ \\
\hline T1 & 109.40 & 11.17 & 84.60 & 4.85 & $<0.001^{*}$ \\
\hline T3 & 102.80 & 10.08 & 78.87 & 5.91 & $<0.001^{*}$ \\
\hline T5 & 87.93 & 8.30 & 70.73 & 5.42 & $<0.001^{*}$ \\
\hline
\end{tabular}

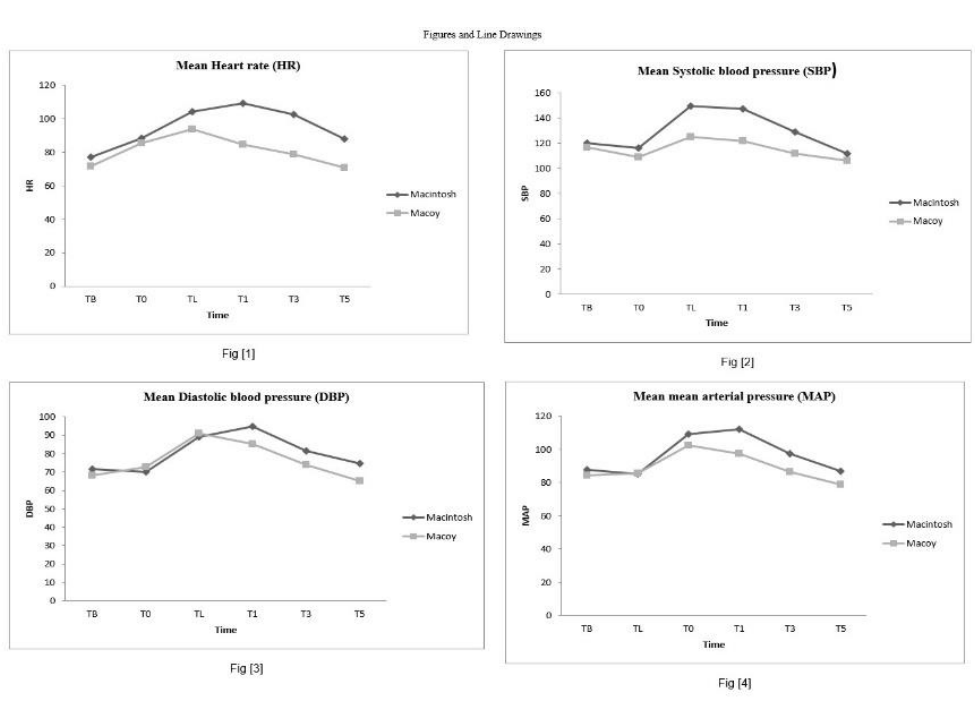

\section{Discussion}

The McCoy levering laryngoscope differs from the Macintosh blade in four aspects. It has a hinged tip, a lever at the proximal end, a spring-loaded drum and a connecting shaft. The hinged tip blade controlled by a lever on the handle of the laryngoscope facilitates elevation of the epiglottis at the same time decreases the overall laryngoscopic movement. ${ }^{13}$ Due to this unique design the McCoy laryngoscope has two advantages over the Macintosh laryngoscope.First due to flexible tip less force is applied during laryngoscopy and the stress response is reduced. Secondly laryngoscopic visualization may be improved by lifting the epiglottis. ${ }^{14}$

It is seen that amount of force exerted during laryngoscopy and intubation determines the stimulation of the stretch receptors present in the respiratory tract. This directly affects the stress response in a linear way. If more force is needed then the response may also increase proportionately. ${ }^{19}$ 
McCoy blade was introduced in 1993. Due to its modified design as described earlier, the force exerted during laryngoscopy with this blade is less, so the pressor response is significantly reduced. ${ }^{13}$ The afferent pathway of the laryngoscopic response is via the glossopharyngeal and the vagus nerve ${ }^{15}$ while the efferent response is mediated via the sympathetic nerves. ${ }^{16}$

Laryngoscopy with McCoy blade required only $53 \%$ of the force $(10.1 \mathrm{~N})$ to obtain a clear view of the vocal cords. On the contrary $(18.9 \mathrm{~N})$ force was required using the Macintosh blade.The reason could be that the hinged tip of the McCoy laryngoscope elevates the epiglottis rather than the forward displacement of the attached structures by the Macintosh blade. ${ }^{12}$

The hemodynamic response is proportional to the duration of conventional laryngoscopy and intubation ${ }^{2}$ so in our study we included the cases in which laryngoscopy and intubation was performed within 20 secs to avoid the bias in findings of hemodynamic parameters we needed for our study.

In our study, there was rise in Heart rate, Systolic and Diastolic as well as Mean blood pressure in both the groups, Macintosh as well as McCoy group.But the rise in all the four parameters was significantly higher in the Macintosh as compared to McCoy group. Similar findings were also found in another study by S Singhal, Neha et al. ${ }^{17}$ Our findings of rise in Heart rate after laryngoscopy using McCoy and Macintosh blade both, but statistically more with Macintosh blade, correlates with similar studies by Haidry MA1, Khan et al. ${ }^{18}$ As we know that hemodynamic changes after laryngoscopy and intubation can be detrimental in patients with ischemic heart disease, cerebrovascular diseases etc. use of McCoy blade in such high risk patients can be thought of to reduce the side effects of pressor response.

Tewari Gupta et al. ${ }^{19}$ compared hemodynamic responses in 160 neurosurgical patients using either McCoy and Macintosh blade. They found that McCoy laryngoscope resulted in lesser change in heart rate and blood pressure compared to Macintosh blade, when fentanyl was not used to obtund the response. However, some studies didn't find any significant difference to pressor response when the two different blades were used. ${ }^{20}$

\section{Conclusion}

From our study we came to conclusion that use of McCoy blade produces less hemodynamic response as compared with Macintosh blade.

\section{References}

1. King BD, Harris LC, Greifenstein FE, Elder JD, Dripps RD. Reflex circulatory responses to direct laryngoscopy and tracheal intubation performed during general anaesthesia. Anaesthesiology 1951;12:556-66.

2. Stoelting RK. Circulatory changes during direct laryngoscopy and tracheal intubation -influence of duration of laryngoscopy with or without prior lidocaine. Anaesthesiology 1977;47(4):381-4.

3. Hamill JF, Bedford RF, Weaver DC, Colohan AR. Lidocaine before endotracheal intubation: Intravenous or laryngotracheal? Anaesthesiology1981;55:578-81.

4. Kautto UM, Heinonen J. Attenuation of circulatory response to laryngoscopy and tracheal intubation: A comparison of two methods of topical anaesthesia. Acta Anaesthesiol Sc and 1982;26:599-602.

5. Vucevic M, Purdy GM, Ellis FR. Esmolol hydrochloride for the management of the cardiovascular stress responses to Laryngoscopy and tracheal intubation. Br. JAnaesth 1992;68:529-30

6. Yaku H, Mikawa N, Maekawa N, Obara H. Effects of verapamil on the cardiovascular responses to tracheal intubation.Br. JAnaesth 1992;68:85-9.

7. Wig J, Sharma M, Baichoo N, Agrawal A. Nicardipine and Verapamil attenuate the pressor response to laryngoscopy and intubation. Can J Anaesth 1994;41:1185-8.

8. Casati A, fanelli G, Albertin A, Deni f, Daneili G, GritoniF, Torri G. Small doses of remifantinil or sufentanil for blunting cardiovascular changes induced by tracheal intubation: A double blind comparison. Eur J Anaesthesiol 2001;18:108-12.

9. Nishiyama T, Higashizawa T, Bito H, KonishiA, Sakai T. Which laryngoscope is the most stressful in laryngoscopy -Macintosh, Miller, or McCoy? Masui 1997;46:1519-24.

10. BraudeN, Clements EAF, Hodges UM, Andrews BP. The pressor response and laryngeal mask insertion -a comparison with tracheal intubation Anaesthesia, 1989;44:551-4.

11. Wood M L, ForrestET, The hemodynamic response to insertion of the laryngeal mask airway: a comparison with laryngoscopy and intubation. ActaAnaesthesiolScand. 1994;38:510-3.

12. McCoy EP, Mirakhur RK, Rafferty C, Bunting H, Austin B A. A comparison of the forces exerted during laryngoscopy: The Macintosh versus the McCoy blade. Anaesthesia 1996,51:912-5.

13. McCoy EP, Mirakhur RK. The levering Laryngoscope Anaesthesia1993; 48: 516-9.

14. Uchida T, Hikawa Y, Saito Y, Yasuda K. The McCoy levering laryngoscope in patients with limited neck extension. Can J Anaesth 1997;44:674-6.

15. Shimoda O, Ikuta Y, Isayama S, Sakamoto M, Terasaki H. Skin vasomotor reflex induced by laryngoscopy: comparison of the McCoy and Macintosh blades. Br J Anaesth 1997;79:714-8.

16. McCoy EP, MirakhurRK, McCloskey BV, A comparison of stress response to laryngoscopy. The Macintosh versus the McCoy blade. Anaesthesia .1995 Nov;50 (11):943-6.

17. S Singhal, Neha, Hemodynamic response to laryngoscopy and intubation: Comparison of McCoy and Macintosh laryngoscope. The Internet Journal of Anaesthesiology .2007; Volume 17 Number 1.

18. Haidry MA, Khan FA, Comparison of hemodynamic response to tracheal intubation with Macintosh and McCoy laryngoscope. Journal of Anaesthesiology Clinical Pharmacology Yr.2013|vol.29|Issue 2|Pg.196-9.

19. Tewari P, Gupta D, Kumar A, Singh U, Opioid sparing during endotracheal intubation using McCoy laryngoscope in Nerosurgical patients: The Comparison of Haemodynamic changes with Macintosh blade in a randomized trial. J Postgrad Med 2005;51:260-4.

20. Forbes A M., Dally F G. Acute Hypertension during induction of anaesthesia and endotracheal intubation in normotensive man. Br J Anaesth 1970;42:618-24. 